\title{
Review of Interventions for Inclusion of Children With ASD and Anxiety in Education
}

\author{
Christine K. Syriopoulou-Delli ${ }^{1}$, Stavroula A. Polychronopoulou, ${ }^{2}$ \\ Gerasimos A. Kolaitis ${ }^{3} \&$ Alexandros-Stamatios G. Antoniou ${ }^{4}$ \\ ${ }^{1}$ Department of Educational and Social Policy, University of Macedonia, Greece \\ ${ }^{2}$ Department of Primary Education, National and Kapodistrian University of Athens, Greece \\ ${ }^{3}$ Department of Child Psychiatry, School of Medicine,National and Kapodistrian University of Athens, "Aghia \\ Sophia" Children'sHospital, Greece \\ ${ }^{4}$ Department of Primary Education, National and Kapodistrian University of Athens, Greece \\ Correspondence: Christine K. Syriopoulou-Delli, Department of Educational and Social Policy University of \\ Macedonia, 156 Egnatia str. PC54336 Thessaloniki, Greece. Tel: 030-693-870-4339. E-mail: \\ csyriop@gmail.com
}

Received: November 18, 2019 Accepted: December 14, 2019 Online Published: January 5, 2020

doi:10.5539/jedp.v10n1p1 URL: http://doi.org/10.5539/jedp.v10n1p1

\begin{abstract}
Background: Anxiety is one of the most common accompanying symptoms in people with autism spectrum disorder (ASD), and may compound the difficulties they experience in social inclusion.
\end{abstract}

Objective: Review of methods and programs that have been developed for the management of anxiety symptoms in individuals with ASD, to help them cope with their social environment, and in particular, school.

Methods: A search for papers published from the 1980s to 2017 was made in PubMed and in the official websites of the US Food and Drug Administration (FDA), the American Association of Anxiety and Depression, UCLA PEERS, Sutherland House School and Autism Speaks, and in the US National Institute of Health (NIH) publications. In addition, other resources were found in the library of the University of Macedonia and the Greek National Research Foundation.

Results: The search revealed papers on anxiety in ASD and its treatment, and three reports of training programs that had been developed specifically for enhancement of the inclusion of people with ASD and anxiety. The papers were reviewed with a view to identifying the components that decrease anxiety and have long-term effects in curtailing social exclusion. Programs incorporating a variety of methods, including intervention in the school curriculum, development of CBT and other psycho-social approaches and promotion of family support, can all increase awareness of anxiety stimuli and lead to successful and sustained management of anxiety symptoms and enhanced social inclusion. Assessment of anxiety in children and young people with ASD is imperative, and efficacy of the intervention needs to be evaluated using evidence-based measurement.

Conclusion: Intervention programs based on recognition and management of anxiety symptoms can increase the possibilities for adaptation and social inclusion of children and young people with ASD. Evaluation of the efficacy of interventions is an area that requires attention.

Keywords: inclusion, anxiety, autism spectrum disorder, treatment, school, family

\section{Introduction}

Autism spectrum disorder (ASD) as defined by the Diagnostic and Statistical Manual of Psychiatric Disorders (DSM-5), is characterized by qualitative weaknesses in social interaction and communication, and limited, repetitive and stereotypical patterns of behavior, interests and activities (APA, 2013). The rate of diagnosis of ASD has risen dramatically over the last decade, and recent estimates show that 1 in 88 may present a developmental disorder in the autism spectrum. The majority of those diagnosed with ASD are males, with a male-female ratio of 5:1 (Centers for Disease Control and Prevention, 2012).

ASD often shows co-morbidity with other psychiatric disorders (Matson \& Nebel-Schwalm, 2007), of which anxiety disorders represent the most common problem in schoolchildren and adolescents with ASD (Ghaziuddon, 
2002). Anxiety interacts with the main features of the ASD, which complicates evaluation of the ASD symptoms, especially when the person with ASD is under stress or social pressure (Kim et al., 2000).

A number of anxiety disorders have been described in ASD, including general anxiety disorder (GAD), social phobia, specfic phobias, separation anxiety, post-traumatic stress disorder (PTSD) and obsessive-compulsive disorder (OCD), of which GAD and OCD in particular have been associated with ASD in samples of young people (Kim et al., 2000; Leyfer et al., 2006; van Steensel et al., 2011).

Anxiety is among the most common coexisting conditions in young people with ASD, with studies showing that many children with ASD meet the criteria for anxiety disorders (Simonoff et al., 2008; MacNeil et al., 2009; White et al., 2009). Anxiety in young people with ASD can aggravate their social deficits, undermine their daily living skills and impair their relationships with peers, teachers and even family members (Drahota et al., 2011; Kim et al., 2000).

Researchers from the University of Amsterdam, from review of 31 studies focusing on anxiety disorders in children with ASD under 18 years of age, concluded that about $40 \%$ of children with ASD had at least one symptom consistent with anxiety disorder (van Steensel et al., 2011). Table 1 presents the prevalence of the specific anxiety disorders in young people with ASD reported in the studies reviewed.

Table 1. Review of anxiety in young people with autism spectrum disorder: specific anxiety disorders detected

\author{
Special phobia $30 \%$ \\ Obsessive-compulsive disorder $17 \%$ \\ Social anxiety disorder / agoraphobia $17 \%$ \\ Generalized anxiety disorder $15 \%$ \\ Anxiety disorder 9\% \\ Panic disorder $2 \%$
}

(vanSteensel et al., 2011).

Children with ASD have more severe symptoms of phobia, persistence, compulsion, kinetics and vocal fears and social phobia than other groups of children. Even in the absence of a formal diagnosis, anxiety is a serious factor in the daily lives of many children and adolescents with ASD, making it difficult for them to perform many everyday things, such as initiating and maintaining friendships, going shopping or taking public transport.

The distinction of features of ASD from anxiety is not easy, as the symptoms may overlap, and diagnosis requires professional assessment (Lecavalier et al., 2014). Nervous or repetitive behaviors can be due to the ASD or may be anxiety manifestations. Children with ASD express anxiety in many of the same ways as children of typical development (TD). Separation anxiety often appears when children have to leave their parents to go to school. Many children are worried about and preoccupied with challenges such as friends, school, health issues, and later, work. These are challenges that affect children with and without ASD, but social anxiety, or fear of social situations, is particularly common among children with ASD.

Children suffering from anxiety may feel strong internal tensions, manifest as tachycardia, muscle tension, sweating and stomachache. Heightened anxiety, even in children of TD can result in repetitive behaviors that appear to serve no function, such as fragmenting paper or fabric, which are considered characteristic of ASD. People with ASD often have difficulty communicating verbally and non-verbal manifestations of anxiety can be the only indication that something is troubling them.

Data on children of TD reveal that childhood anxiety that has not been treated adequately can lead to long-term psychopathology (Pine et al., 1998). Children with ASD may have similar long-term consequences from undiagnosed and untreated anxiety, compounding their social, cognitive and linguistic weaknesses.

Evidence for the efficacy of treatment of childhood anxiety disorders in children of TD is robust. Successful treatment strategies are based mainly on cognitive behavioral therapy (CBT) (Warwick et al., 2017) and pharmacotherapy, specifically selective serotonergic reuptake inhibitors (SSRIs) or a combination of the two (Walkup et al., 2008).

In contrast, data on the treatment of anxiety in young people with ASD are scarce. A number of reviews referring to treatment of anxiety in young people with high functioning autism (HFA) support the efficacy of CBT (Lang et al., 
2010; Moree \& Davis, 2010; Nadeau et al., 2011; Wood, 2013; Rudy et al., 2013; Sukhodolsky et al., 2013). Indicatively, CBT is used effectively to stop recurring anxiety in children with at least verbal skills. The first step in this process teaches the children to recognize the root of their fears, for example fear of permanent separation when leaving their mother to go to school. After acknowledging the fears that they perceive, the individuals can be helped by the therapist, by gradual exposure of to the anxiety stimulus, allowing them to deal with these fears in a progressive manner, by "small steps". As an example, the child first spends a minute in a room without her/his mother, and when the mother reappears, the child confirms that she was safe, and then spends ever longer periods away from his/her mother, providing the proof needed to and put anxiety aside and feel safe.

Other reviews comment on the lack of data from pharmacological studies and underline the need for more clinical testing in this population (Nadeau et al., 2011; Rudy et al., 2013). A range of other specific tools used to improve the functionality of young people with ASD and HFA anxiety have also been reviewed (Wigham \& McConachie, 2015), including exercise, stress management skills, coping skills, social and life skills, meditation, yoga, eating non-soy or excitoxins such as monosodium glutamate (MSG), and home teaching (to relax the pressure of demands for perfection and social phobia), in some cases in combination with medication (Syriopoulou et al., 2018).

Although deficits in social function are a key feature among people with ASD, meta-analysis of social behavior intervention studies for these individuals has not shown large, socially significant, long-term or generalized changes in social capability (White et al., 2007; Rao et al., 2008; Reichow \& Volkmar, 2010; Matson et al., 2007). A possible explanation for the poor results may be that these interventions often occur in out-of-context settings, such as clinical or community centers for mentally disabled/retarded people, leading to inadequate conservation and generalization of results (Gresham et al., 2001).

Reichow \& Volkmar (2010) presented a synthesis of good results from social skills interventions for people with ASD, reviewing 66 studies published between 2001 and 2008. Although the most common intervention environment was the school or preschool (19 out of 25), only 3 of the 66 studies included social skills interventions for adolescents, none of which took place in a school setting, and none specifically addressed anxiety (Reichow \& Volkmar, 2010).

The Individuals with Disabilities Education Improvement Act (IDEIA) provides that students with disabilities, including those with ASD, receive support in a less restrictive environment (Sitlington \& Clark, 2007). The classroom is often considered the least restrictive environment for students with disabilities (Lang \& Page, 2011) as it is familiar to them and close to their living environment, and is a place where children can apply targeted skills with peer children, most likely to lead to greater generalization (Laugeson et al., 2014). For people with ASD, social skills learned and tested in laboratories or clinics may not be used and necessarily applied to everyday life at home or at school (Reichow \& Volkmar, 2010). For this reason, school-based research, with efficacy studies on social skills intervention are important for children and adolescents with ASD (Hart \&Whalon, 2011; Rao et al., 2008; White et al., 2007).

Moote and colleagues (1999) reviewed 25 school-based studies of social skills interventions, not specifically for students with ASD, conducted between 1986 and 1998 with participants in grades 5 and 12; 16 of these studies were conducted in general education training environments, 8 in special education settings and one on an academic day in a treatment environment. Of these, 14 of reported profitable results for the participants, 9 limited or mixed results, and 2 concluded that the outcome of social skills interventions were not effective. The authors pointed out that the field of social skills education in a school environment was at an early stage of development and that the findings should be examined with moderate enthusiasm. (Moote et al., 1999)

A meta-analysis by January and colleagues (2011) of 28 articles published from 1981 to 2007, assessing the effectiveness of classroom interventions to improve social skills for pupils of all ages, focused on prevention rather than reaction. The interventions were aimed at reducing the number of pupils at risk of later behavioral problems and school failure, and included classes with children of TD and those with social difficulties. Studies involving school intervention designed for children with developmental disorders such as ASD were not included in the analysis. The meta-analysis showed that classroom interventions aimed at instruction in improving social behavior have a small effect $(0.15)$, but that those involving more experimental approaches, such as social activities and role play, were more effective than those centered on discussion or instruction. Intervention in early childhood was generally more effective than programs for older children and teenagers. The authors suggested that these results should be interpreted with care, but that a higher frequency (i.e., on average, twice weekly) and parental involvement may be important for achieving more effective results (January et al., 2011).

Examination of social skills interventions specifically targeting students with ASD shows similar results, but 
further research is needed. In a review of 13 social performance interventions for children with ASD (White et al., 2007), only 2 interventions took place in a school setting. Bellini and colleagues (2007) conducted a meta-analysis of 55 studies published between 1986 and 2005 on the effectiveness of school social interventions for children and adolescents with ASD. The interventions yielded moderate results for maintenance of social skills and low generalization results. Comparing age groups, higher acquisition of social skills from intervention, generalization and maintenance of effects were observed in teenagers, but only 9 of the studies were on this group (Bellini et al., 2007).

While few studies have been reported on that teach social skills to adolescents with ASD in the school environment, several studies have shown school-based programs to be effective in improving social skills and social networks for younger schoolchildren with ASD (Chan et al., 2009; Kamps et al., 1992; Pierce \& Schreibman 1997; Harper et al., 2008; Morrison et al., 2001; Licciardello et al., 2008; Lang et al., 2011). Classroom social skills groups are rare compared with other interventions such as peer mediation interventions; among 22 studies reviewed that focused on social skills and self-help skills in people with ASD, only 3 used a group social skills method and all took place outside the classroom (Flynn \& Healy, 2012).

Although some social skills programs have been found to be effective with young children at school (Chan et al., 2009; Kasari et al., 2012; Pierce \& Schreibman 1997; Harper et al., 2008; Morrison et al., 2001) various constraints have been identified. In a meta-analysis of the effectiveness of 28 social skills classroom interventions, only one study systematically matched the type of intervention strategy with the type of skills weaknesses of the children with ASD, and only half of the studies measured the reliability of the treatment (January et al., 2011). In addition, only 12 of the studies gathered information on social credibility and inquired whether teachers found the interventions useful to their pupils. A survey conducted with 49 special education teachers (Boardman et al., 2005) showed that when choosing an intervention for their class, teachers do not consider whether intervention is research-based, but rather whether intervention is feasible, appropriate for their students and includes professional development support. It appears that lack of guidelines, treatment credibility, and social credibility may have contributed to the low level of effect foundin themeta-analysis.

In a review of teacher involvement in intervention studies for children with ASD, Lang and colleagues (2010) examined 49 studies from 1996 to 2008, revealing that the most common classroom interventions included embedded guidelines, social stories, and activity or interventions in a picture program. Of the teachers who performed these interventions in 38 of the 49 studies, most (34/38) reported positive results, and the other 4 mixed results. An important consideration is the ability of teachers to accurately implement a given intervention and to ensure that all elements are followed according to the protocol, but teaching intervention procedures were described in 17/49 studies and treatment reliability was reported in only 13/49 studies. Concerning maintenance of the skills learned during the intervention, only 12/49 indicated assessment at from 10 days to one year following the end of the intervention, but all reported positive results. Finally, the social reliability reported was generally positive and suggesting that the interventions used were acceptable to the teachers, but many studies included only subjective measurements and only a few used experimentally reliable measurements (Lang et al., 2010). Interpretation of positive results according to teachers should therefore be made with caution.

The limited bibliography available on school-based interventions for social skills in children with ASD limits the strength of the findings (White et al., 2007; Bellini et al., 2007). The possible benefits of adolescent education in social skills at school are not well documented and such interventions are often provided as part of the overall educational program of the school, and do not include anxiety management (Hess et al., 2008). Given IDEIA's commitment to providing research-based support to students with disabilities in the less restrictive environment (Sitlington \& Clark, 2007), the importance of designing, implementing and examining interventions for development of social skills in the school environment for adolescents with ASD is paramount, and the issue of anxiety in this population should be addressed (Laugeson et al., 2014).

Most of the papers on treatment of anxiety in people with ASD describe an individualized approach to treatment, and there is little information on programs to manage anxiety and increase the educational and social inclusion of children and adolescents with ASD. The lack of empirically based school social interventions for adolescents with ASD represents a gap in the research literature. This review focused on studies of programs on the management of anxiety symptoms in this population in a framework which would facilitate their inclusion in the educational setting.

\section{Methods}

This review of the international literature was guided by the following questions: 
1) What methods and programs have been developed with the aim of facilitating the inclusion of individuals with ASD and anxiety in school and in the wider social environments?

2) In what ways are individuals with ASD supported in overcoming their exclusion from educational settings?

3) What psycho-pedagogical interventions are suggested for supporting the integration of children with ASD into the school environment?

4) What psycho-pedagogical interventions can be planned in the general or special school?

The selection of the studies for the purpose of this paper was based on two criteria. First, the participants in the research study sample had to be diagnosed with ASD and anxiety symptoms, and second, the programs had to include interventions for training of people with ASD directed towards relieving their anxiety and promoting their social inclusion.

Research papers, reviews and meta-analyses were searched in PubMed and on the official websites of the US Food and Drug Administration (FDA), the American Association of Anxiety and Depression, Autism Speaks, UCLA PEERS, the Sutherland House School, and the publications of the US National Institute of Health (NIH), for the period from the 1980s to 2017. In addition, other resources were found in the library of the University of Macedonia and the Greek National Foundation of Research.

The practical value of this review lies in exploring the theoretical basis and deriving recommendations on the design of interventions in the educational environment of individuals with ASD and anxiety in order to increase their social and educational inclusion of individuals with ASD, based on experience with specific methods and programs.

\subsection{Literature Review Findings}

The literature search revealed several studies and reviews on the diagnosis and management of anxiety in children and young people with ASD, and reports of three specific school intervention programs (Table 2).

Table 2. Publications on programs designed to manage anxiety in children and young people with autism spectrum disorder (ASD) in order to overcome social exclusion

Theoretical Basis and Management based on Cognitive Behavioral Therapy (CBT)

1. Myles, 2003. Behavioral forms of stress management for individuals with Asperger syndrome.

2. Sofronoff et al.2005. A randomized controlled trial of a CBT intervention for anxiety in children with Asperger syndrome

3. Chalfant et al., 2007. Treating anxiety disorders in children with high functioning autism spectrum disorders: A controlled trial.

4. Fujii et al., 2009. Intensive CBT for anxiety disorders in school-aged children with autism: A preliminary comparison with treatment-as-usual.

5. Wood et al., 2009. CBT for anxiety in children with autism spectrum disorders: A randomized, controlled trial.

6. Lang et al., 2010. Treatment of anxiety in autism spectrum disorders using CBT: A systematic review.

7. Moree et al., $2010 \mathrm{CBT}$ for anxiety in children diagnosed with autism spectrum disorders: Modification trends.

8. Drahota et al., 2011. Effects of CBT on daily living skills in children with high-functioning autism and concurrent anxiety disorders.

9. Reaven et al., 2012. Group CBT for children with high-functioning autism spectrum disorders and anxiety: A randomized trial.

10. McNally et al., 2013. Behavioral management of stress for people with Asperger Syndrome.

11. Rudy, B. et al., 2013. Managing anxiety comorbidity in youth with autism spectrum disorders.

12. Sukhodolsky et al., 2013. CBT for anxiety in children with high-functioning autism: A meta-analysis

Application: Specific programs

1. The PRECISE frame. Deficits of social skills in high-functioning young people with ASD. Kim et al., 2000, Chalfant et al., 2007

2. The Sutherland House School. January et al., 2011, McConachie et al., 2013 
3. UCLA PEERS. White et al., 2007, Reichow and Volkmar, 2010, Laugeson et al., 2014,

$\underline{\text { Parental involvement }}$

Fight / Facing your fears. Reaven et al., 2009

Not surprisingly, most of the ASD programs designed for reducing anxiety and promoting inclusion are directed at children and young people with HFA. Many of the strategies incorporated are based on behavioral and cognitive methods. Several types of CBT have been developed to manage anxiety in children and adolescents with ASD, with promising results from various research centers (Myles, 2003; Sofronoff et al., 2005; Chalfant et al., 2007; Fujii et al., 2013; Wood et al., 2009; Drahota et al., 2011; Reaven et al., 20120).

Techniques include combating negative thoughts with logic, role playing, patterns of encouraging behavior and gradual (step-by-step) exposure to fear situations. Many of these programs are adapted from treatments originally developed for young people of TD. Programs for children often incorporate their individual special interests to encourage participation. For example, the therapist can use the children's favorite childlike characters to shape coping skills or to engage in discussions about special interests or passions during the treatment session to promote motivation and engagement.

CBT uses gradual exposure/stimuli, or taking small steps to deal with anxiety, with attention to the conditions of the sessions, as well as teaching methods for recognition of anxiety triggers and relaxation techniques. It also uses cognitive reconstruction, or the acknowledgement and change of unreasonable thoughts, and the formation of more appropriate thinking. CBT is based on the premise that working to change 'mis'behavior (e.g., maximizing the negative) can lead to changes in the abnormal behaviour, seeking to educate a person to understand how they process the world about them, and then to acquire skills to enable them to apply a new way of seeing things. Various issues may arise, however, when using the traditional CBT with children and adolescents with ASD. CBT is word-based and often quite abstract, which may cause problems with this group, and Moree\& Davis (2010) found that incorporating more visual material and specific interests help this group, as well as exploiting parental involvement.

It has been suggested that the CBT may not work as well with people with ASD because of their impairment in mind theory (a skill needed to engage in CBT strategies) but improvement has been documented in high performance children with ASD and anxiety after CBT (Wood et al., 2009).

Among practical instructions addressing anxiety the American Association of Anxiety and Depression (Powers et al., 2016) has recommended that attention should be devoted to various specific aspects, including: Staying in the present: practitioners should apply treatments focussed on the "here" and "now" principles rather than examining and treating what happened in the past. Studies have found that the practice of thinking for the present through reflection can help reduce levels of stress and anxiety. Perfection: Many children with anxiety measure themselves in terms of an impossible ideal of "perfection". Life is imperfect. Teaching children that no one is perfect and that they have to manage themselves, rather than comparing themselves with each other.

Several programs for the development of interventions have been designed to manage anxiety symptoms in child's physical environment. Some recommend approaches for teachers, others involve parents, others propose interventions in the school curriculum or in the environment (e.g., the low arousal environment) (Lord et al., 2002; Nauta et al., 2004, Warwick et al., 2017).

Autism Speaks continues to support research into these and related behavioral anxiety relief interventions, and reviews and meta-analysis document positive short-term results, although studies are needed to investigate the long-term maintenance of the beneficial effects (Lang et al., 2010; Sukhodolsky et al., 2013). It is accepted that intervention programs in the familiar environment of the school are likely to meet with greater success, and the literature search produced three well-planned examples.

\section{Specific Intervention Programs for Management of Anxiety and Inclusion of Children and Young People with ASD}

\subsection{PRECISE}

One of the first attempt to organise interventions for this population was the PRECISE framework, introduced in the USA (Kim et al., 2000; Chalfant et al., 2007).

As shown in Table 3, PRECISE is an acronym for the components of the framework, which is used to monitor cognitive approaches. It was designed according to the Theory of the Mind, the Executive Function and the 
Executive Operation (Joseph \& Flusberg, 2004), and includes a set of objectives that a professional should think about when applying interventions with children or young persons (Table 3).

Table 3. The PRECISE Clinical application of cognitive behavioral therapy (CBT) for children and young people with autism spectrum disorder (ASD)

\begin{tabular}{lll}
\hline Based upon & P & Partnership working \\
Pitched at the & R & Right developmental level \\
Promotes & E & Empathy \\
Is & C & Creative \\
Encourages & I & Investigation and exploration \\
Facilitates & $\mathbf{S}$ & Self-discovery and experimentation \\
Is & $\mathbf{E}$ & Enjoyable \\
\hline
\end{tabular}

Kim et al., 2000; Chalfant et al., 2007.

\subsubsection{Partnership Working}

It is important when working with a child to clearly define the goals of the job you are going to perform, and provide clear written information on the structure of the course and what the child can expect to happen. Some children can benefit from a written program.

\subsubsection{Right Developmental Level}

When you work with a children or young people with ASD, it is important to approach in a way appropriate to the developmental stage and also any difficulty the person may experience in relation to anxiety. Check with the children that the information has been properly understood. Specific, clear language must always be used and, if possible, to incorporate the individual child's language style and words into the dialogue.

An emotional diary is useful and helps some children understand their feelings and recognize feelings, and children can also benefit from the use of visual clues that show emotions. Use of calendars and job segmentation charts are also helpful ways to help children overcome their difficulties.

\subsubsection{Empathy}

Children and young people with ASD may become overly attached to some interests and get involved in lengthy discussions about them. When a child or young person exhibits such behavior during a session, it is helpful to interrupt that child firmly and engage in a conversation about communication issues rather than continue listening. It is also useful to explore social skills and, if necessary, to limit social exchange and adopt a more action-oriented approach. Non-verbal communication such as eye contact, facial expressions and gestures may not be recognized or understood.

\subsubsection{Creativity}

A creative approach using cartoons, videos, pictures and games can all be used with children with ASD. This can be simple by communicating with text through a written note. Digital cameras can be used to photograph places and situations that the children may find difficult to fuel the conversation and help them overcome the difficulties. Incorporating events from the everyday life of the child can be useful, but also the use of fictional characters, e.g. Harry Potter. The device of a "box of emotions" can be effective, for example finding the tool to "repair the feeling".

\subsubsection{Investigation and Exploration}

Children may be encouraged to explore their feelings through the use of questions and playing a role. For some children it may be necessary to provide lists of alternatives to think about in a number of situations, for girls it may be useful to be asked to play the role of someone they admire.

\subsubsection{Self-Discovery and Experimentation}

Children can be encouraged to understand their feelings and thoughts, and those of others, by using games, such as playing the explorer, the detective, the astronaut. 


\subsubsection{Enjoyable}

A creative approach should be employed to make their work fun for the children and so they do not feel it is too hard or laborious.

\subsection{The Sutherland House School}

The Sutherland House Schoolin the UKuses a weekly staff teaching system to work on the development of interaction and emotional well-being (Dang et al., 2017; Oono, Honey, \& McConachie, 2013). It is considered important that whatever work is done in the school in this area is conducted in cooperation with other adults who are involved and with the support of families. Sutherland House School holds weekly personal teaching sessions for pupils aged 3-19 years with ASD. These consist of about 50 minutes with an individual staff member, focusing on managing anxiety and on developing social interaction, emotional understanding, self-awareness, problem-solving skills, anger management, understanding choices and expression of preferences. Some of the key elements that make this approach effective are a combination of the commitment of the staff to the program and the example of managers, who participate in the educational activities.

One of the basic principles of the program is building the message, in cooperation with the students themselves, of accepting people, of encouraging development in each student and at every level, and of working collaboratively with families and other professionals. A system is in place for training and support of the staff involved and for recording of process and progress.

When a participant in the program presents symptoms of anxiety, a variety of techniques and strategies are applied to help to reduce the effects, adapted to suit each person's personal characteristics the ways they are affected by anxiety. It is often found useful to start with a reduction of sensory stimuli. Once the students involved feel safe, personalized techniques of distraction and anxiety reduction are introduced. These may be related to individual personal interests, or involve deep breathing and yoga, or sensory modulation approaches, such as weight blankets or deep-pressure massage may be administered, as appropriate. When the children are younger they will need adults to implement these strategies for them, but as they mature it is important for them to learn to recognize the signs of anxiety in themselves and to develop a series of relaxation strategies, so that they can use whatever suits the individual and the situation best.

\subsection{The UCLAPEERS Program}

PEERS is an acronym for the Program for Education and Enrichment of Relationship Skills, developed in Los Angeles, but applied in other centers in the US. Individuals with ASD taking part in the PEERS participate in an intervention or alternative curriculum for social skills within the school system. Instruction is provided daily by class teachers for 14 weeks. The program outline is shown in Table 4.

Table 4.Overview of the Program for Education and Enrichment of Relationship Skills (PEERS) curriculum

\begin{tabular}{|c|c|c|c|}
\hline Week & Didactic lessons & Description of the lessons & Homework \\
\hline 1 & $\begin{array}{l}\text { Introduction } \\
\text { andtradinginformation }\end{array}$ & $\begin{array}{l}\text { Teens are taught how to trade information } \\
\text { duringconversations with peers in order to find } \\
\text { common interests }\end{array}$ & $\begin{array}{l}\text { Teens practice trading information on } \\
\text { the phone with a classmate }\end{array}$ \\
\hline 2 & Conversational skills & $\begin{array}{l}\text { Teens are instructed on key elements of having a } \\
\text { two-wayconversation with peers }\end{array}$ & $\begin{array}{l}\text { Teens practice trading information on } \\
\text { the phonewith a non-classmate }\end{array}$ \\
\hline 3 & $\begin{array}{l}\text { Electronic } \\
\text { communication }\end{array}$ & $\begin{array}{l}\text { Teens learn about the appropriate use of } \\
\text { voicemail, email,text messaging, instant } \\
\text { messaging, and the Internet infurther developing } \\
\text { pre-existing friendships }\end{array}$ & $\begin{array}{l}\text { Teens practice using electronic forms } \\
\text { of social communication }\end{array}$ \\
\hline 4 & $\begin{array}{l}\text { Choosing } \\
\text { friends }\end{array}$ & $\begin{array}{l}\text { Teens are introduced to the social hierarchy of } \\
\text { social groupsin schools and begin to identify } \\
\text { groups they might fit inwith. Teens begin to } \\
\text { identify extra-curricular activities based on their } \\
\text { interests }\end{array}$ & $\begin{array}{l}\text { Teens begin to pursue } \\
\text { extra-curricular activitiesand identify } \\
\text { potential social groups where they } \\
\text { begin trading information with } \\
\text { members ofthese groups }\end{array}$ \\
\hline 5 & $\begin{array}{l}\text { Appropriate use of } \\
\text { Humor }\end{array}$ & $\begin{array}{l}\text { Teens learn the basic rules around appropriate } \\
\text { use of humorand learn to pay attention to their } \\
\text { humor feedback todetermine if they are more of }\end{array}$ & $\begin{array}{l}\text { Teens pay attention to their humor } \\
\text { feedback todetermine if people are } \\
\text { laughing at them, laughing with }\end{array}$ \\
\hline
\end{tabular}




\begin{tabular}{|c|c|c|c|}
\hline & & a joke-teller, joke-receiver, orjoke-refuser & them, or not laughing at all \\
\hline 6 & Peer entry strategies & $\begin{array}{l}\text { Teens are given instruction about the precise } \\
\text { steps involvedin joining group conversations } \\
\text { with peers }\end{array}$ & $\begin{array}{l}\text { Teens practice entering group } \\
\text { conversations with peers }\end{array}$ \\
\hline 7 & Peer exit strategies & $\begin{array}{l}\text { Teens are taught how to assess receptiveness } \\
\text { during peerentry and how to gracefully exit } \\
\text { conversations when theyare not accepted }\end{array}$ & $\begin{array}{l}\text { Teens practice entering and exiting } \\
\text { groupconversations with peers }\end{array}$ \\
\hline 8 & Get-togethers & $\begin{array}{l}\text { Teens are given instructions about how to plan } \\
\text { andimplement successful get-togethers with } \\
\text { friends }\end{array}$ & $\begin{array}{l}\text { Teens organize and host a } \\
\text { get-together with potential friends } \\
\text { not affiliated with PEERS }\end{array}$ \\
\hline 9 & Goodsportsmanship & $\begin{array}{l}\text { Teens are taught the rules of good } \\
\text { sportsmanship }\end{array}$ & $\begin{array}{l}\text { Teens practice good sportsmanship } \\
\text { while playing video games, } \\
\text { computer games, board/cardgames, } \\
\text { and sports }\end{array}$ \\
\hline 10 & Handling verbalteasing & $\begin{array}{l}\text { Teens are taught how to appropriately respond to } \\
\text { verbalteasing from peers. Teens learn to } \\
\text { differentiate betweenteasing (i.e., verbal } \\
\text { attacks) and embarrassing feedback andhow to } \\
\text { alter their behavior in response to the latter }\end{array}$ & $\begin{array}{l}\text { Teens practice handling verbal } \\
\text { teasing appropriately when relevant }\end{array}$ \\
\hline 11 & $\begin{array}{l}\text { Handling physical } \\
\text { bullying and bad } \\
\text { reputations }\end{array}$ & $\begin{array}{l}\text { Teens are given strategies for handling physical } \\
\text { bullying andhow to change a bad reputation }\end{array}$ & $\begin{array}{l}\text { Teens implement new strategies for } \\
\text { handling bullying and physical } \\
\text { threats from peers whenrelevant }\end{array}$ \\
\hline 12 & $\begin{array}{l}\text { Handling arguments and } \\
\text { disagreements }\end{array}$ & $\begin{array}{l}\text { Teens are given instruction about the important } \\
\text { elementsnecessary to resolving arguments and } \\
\text { disagreements withpeers }\end{array}$ & $\begin{array}{l}\text { Teens practice handling arguments } \\
\text { with peers when relevant }\end{array}$ \\
\hline 13 & $\begin{array}{l}\text { Handling } \\
\text { gossip }\end{array}$ & $\begin{array}{l}\text { Teens are given concrete strategies for } \\
\text { minimizing theeffects of rumors and gossip }\end{array}$ & $\begin{array}{l}\text { Teens practice handling rumors and } \\
\text { gossipappropriately when relevant }\end{array}$ \\
\hline 14 & $\begin{array}{l}\text { Graduation party and } \\
\text { ceremony }\end{array}$ & $\begin{array}{l}\text { Teens are given a review of the skills taught in } \\
\text { the PEERS_curriculum }\end{array}$ & $\begin{array}{l}\text { Teens are rewarded with a graduation } \\
\text { party andceremony on the last day of } \\
\text { the week }\end{array}$ \\
\hline
\end{tabular}

(Laugeson et al., 2014).

The outcome of this approach is promising. The results of an efficacy study showed that, compared with a control group, the participants in PEERS improved significantly in social performance. Their teachers observed better social responsiveness, social communication, social motivation, social sensitivity, and reduced autistic behavior and stereotypical patterns, and the Social Knowledge score in the Social Responsiveness Scale increased after completion of the program (Chang et al., 2013; Brown et al., 1997).

Self-reporting of the teenagers indicated a significant improvement in their social skills with friends and parents. Parental reports, using the Social Anxiety Scale (Ghahari et al., 2017; Brown et al., 1997), showed a reduction in the social anxiety of their adolescent children. This program is one of the few that includes teacher-facilitated interventions that show efficacy in improving social skills in adolescents with ASD in the classroom, one of the most natural social contexts (White et al., 2007; Reichow \& Volkmar, 2010; Laugeson et al., 2014).

\subsection{The role of Parents in the Management of Anxiety in their Children with ASD}

One of the features of the Sutherland House School program is the involvement of parents. Parents have an integral role in helping children with ASD to manage their anxiety, and apart from being parents, they also must be coordinators, supporters and friends (O'Nions et al., 2017).

Parents can play an important role in the treatment of anxiety in their child with ASD, and can be taught to help their children with a variety of techniques for recognizing and managing their anxiety, such as "self-tuning" (Sofronoff et al., 2005). Parents have more opportunity to know their children than anyone else, and to recognize their anxiety triggers. Being sensitized to the anxiety spikes in the child is an important step towards improving the 
management and preventing stress and anxiety. Common triggers may include routine changes, lack of sleep and new social situations.

Parents of children with ASD often feel helpless and can benefit from specific advice and support. The following recommendations shown in Table 3 are part of the "Facing Your Fears" intervention (Reaven et al., 2009).

Table 5. Recommendations to parents from the Face Your Fears program

- $\quad$ 1. Encourage and reward your child for his/her endeavor and for mixing in bold behaviors

- $\quad$ 2. Ignore excessive anxiety

- 3. Distinguish between realistic and unrealistic fears that an appropriate course of healing can be established.

- 4. Show confidence in the child's ability to manage his or her anxieties and stress.

- 5. Show encouraging behavior towards your child.

- $\quad$ 6. Work with your spouse or partner to develop a plan to deal with your fears

- 7. Discuss how to share coping skills and build an exposure hierarchy with the professionals so that what is accomplished in one environment can be generalizing into other situations.

(Reaven, 2009).

\subsection{Forms of Anxiety Management in the Classroom}

Empowering social understanding involves providing immediate assistance and while guidance strategies are beneficial, it is almost impossible to learn all the social skills required. As a result, skills are often taught in an interpretative way since the child has been involved in a problematic approach. This requires an adult to function as a social manager or "operator". Interpretative strategies can help random actions to become meaningful interaction for people with ASD. These include optical symbols, such as cartoons, and social autopsies and strategies related to status, choices and consequences, pragmatism and mind reading, which enhance their understanding of the environment and reduce negative behaviors. Some of these are described below. Social Autopsies: Social autopsy is a method for analyzing a problem of social skills, specifically for managing a social error. The child or young person works with an adult to identify and recognize the error, to determine who is harmed by the mistake, to decide how to correct the mistake, and to develop a plan to prevent the mistake of happening again (Myles, 2003).

The Situation, Options, Consequences, Choices, Strategies, Simulation (SOCCSS) strategy: This adult-assisted strategy helps children and young people with ASD to understand cause and effect and realize that they can affect the outcome of many of the decisions they make. The strategy can be implemented one on one with a child, or it can be carried out as a group activity, depending on the situation and the needs of the pupils (Myles, 2003).

Stop, Observe, Deliberate and Act (SODA): SODA is a visual strategy that has wide application. It helps children and young people think and explore social clues and discuss social reactions to them. SODA allows children and young people to approach new situations without impulsivity and to use social skills in a context that is appropriate (Venter et al., 1992; Vigerland et al., 2017).

Sensory awareness: Several programs appear to be effective in meeting the sensory needs of children and young people with ASD (e.g., How does your machine run? The Awakening Scheme for Self-Configuration; Tools for the Teacher; Parents of the Pupils; Building Bridges through Sensory Integration) (Sood, 2013)

The Stress Tracking Chart, the Summary of Stress Signals Worksheet and the Stress Thermometer are used to help the child the learn the following: To identify and name their feelings using non-verbal and conditional indications. To assign appropriate values to different levels of emotions such as anger.To redirect negative thoughts towards positive thoughts. To recognize environmental anxiety and common reactions.To recognize the early signs of anxiety. To choose relaxation techniques that suit their needs.

Systematic research is required to identify which techniques are best suited for children and young people, the context within which they can be used and methods to ensure that children and young people with ASD and anxiety generalize these skills at school, but also at home and in the community (Myles, 2003).

\section{Discussion}

The aim of this review was investigation of interventions for the treatment of anxiety in people with ASD in school. 
Application of CBT and social interventions, and enrichment and management of the curriculum have been proposed for the support of people in an inclusive environment. The role of parents is important, and the involvement of health care personnel may be indicated, as careful diagnosis of the anxiety is crucial, and some of the students may be receiving medication for their anxiety. Evaluation of the efficacy of intervention should be an integral part of any program.

One of the first challenges identified in the review is related to the difficulties in the diagnosis and measurement of anxiety in children and young people with ASD, as there is overlap in the symptoms (vanSteensel et al., 2011). For example, the obsessions and compulsions of OCD may seem similar to repetitive and stereotyped behaviors in children with ASD. Those most likely to be diagnosed with an anxiety disorder appear to be adolescents who are diagnosed with Asperger syndrome or ASD-HF. This may be because adolescents with relatively high cognitive function may be highly aware of their surroundings and how they are perceived by others, increasing their anxiety. As children with ASD enter puberty, differences between them and peers becomes clearer (Alfano et al., 2006). Alternatively, a child with severe mental disability may experience less anxiety or simply not express anxiety in a way that leads to a formal diagnosis.

Both the design of programs of intervention and the evaluation on their efficacy are based on the availability of good instruments which can detect anxiety and changes in its level (Gresham et al., 2001; Wigham et al., 2015). Various methods and instruments may be used by health professionals, teachers and parents and the students themselves. Consideration should be given to interpretation of the measurements and reports of anxiety, as the levels of stress recorded by parents and teachers may differ from those reported by children and young people themselves (Nauta et al., 2004), and that teachers tend to report significantly higher levels of stressful behavior in the children than parents (Gadow et al., 2005). This may be because parents and teachers report according to different criteria, or it may be that children are more likely to have anxiety symptoms at school than at home. Much work is still needed on the measurement of anxiety in children and adolescents with ASD, not least because the efficacy of intervention programs is assessed partly by change in anxiety level (Piers, Harris, \& Herzberg, 2002).

This review revealed evidence that behavioral interventions help many children and adolescents with ASD and anxiety, and that various applications of CBT can be particularly helpful for high-functioning adolescents and young adults. The school environment is the second environment, after home, where the child spends many hours each day. There is increasing interest in the development of programs for the management of anxiety symptoms in the school environment (Warwick et al., 2017). It is expected that for children and adolescents with ASD the school represents a familiar environment, conducive to understanding, calmness, cooperation and adaptation, and that school intervention will work in favor of developing coping strategies for their anxiety and inclusion skills.

\subsection{General Considerations}

People with ASD are prone to stressful experiences, because of communication difficulties, inability to predict results, deficits in understanding social interaction and differences in sensory processing. When this is compounded by anxiety, there may be changes in their sleep and toilet routine and in eating habits. They may become even less tolerant of changes or social situations and less able to communicate or express emotions. They may become overly attached to special interests or following new or old routines, and show behaviors that avoid co-operation. They may present anxiety-related physical symptoms such as irritable bowel or abdominal swelling.

Apart from specific intervention programs for anxiety in ASD, environmental modifications, both at home and at school can help to reduce anxiety triggers, by 1.reducing confusion and unpredictability, and 2 . increasing a sense of calm. Schools can use a number of strategies, including organizational visual information with clarifying reminders and specific instructions, and problem-solving strategies. Perceptual information can be presented in a visual way, such as the use of symbols to recognize and communicate emotions. Schools with pupils with ASD must increase the awareness of the potential for overload; a child may receive excessive organizational information or intense social interaction, or experience sensory overload. Supportive adults, and especially parents and teachers can help by providing a predictable environment and low stimulation.

Thought should be given to planning for the children when they experience unmanageable levels of anxiety. Children with ASD will have personal spikes for their anxiety, which may be related to disturbed routine, new experiences, particular events (visits to the dentist, doctor, Christmas school events, party, etc.), changes in classes or teachers. These spikes should be anticipated. In addition, the hormonal changes in puberty may be associated with mood changes in adolescence. Teachers cannot withdraw all stress-causing situations, and they do not need to, but they can help prevent anxiety in various ways; by making the child's daily environment predictable, by limiting sensory overload, by giving the child opportunities for systematic relaxation in stressful moments, and by employing at the right moment specific strategies that the child can understand. One of the most important things 
the teacher can do to prevent anxiety from provocative situations is to help the students with ASD to be able to "read" and recognize their behavior or stress levels (White et al., 2009). This will also help the teacher to connect with the child and be able to prevent or calm episodes of anxiety.

Some strategies can be integrated into school curriculum, such as activities that enhance development of self-confidence, self-knowledge, problem-solving strategies and social skills. Development of such skills can help them cope with stress and protect the mental and emotional health of the children with ASD. Schools should be allowed to increase their flexibility to meet the individual needs of their students, building on relaxation and emotional well-being techniques and personal strategies to manage anxiety and anger. Space needs to be made in the school program for additional sessions that offer emotional well-being. Some schools build on regular but short sessions with students at the beginning or the end of the day, others may use the assembly time. The work of the curriculum can be linked to Personnel Social Health Education (PHSE), encompassing individual development, citizenship and career (White et al., 2009)

\subsection{Specific Forms of Management}

Certain behavioral forms of stress management can be applied by teachers for children and young people with ASD, who when experiencing anxiety can react by showing provocative behavior. This does not happen in isolation or by accident, but is an attempt to communicate. Anger or rage is often experienced in a number of stages that lead to an overt incident or episode. These are: 1 . the stage of hurt, 2. the stage of anger, and 3. the recovery stage. (White et al., 2009)

The stage of hurt: In the first stage the behavior may seem minimal, such as clearing the throat or tapping the foot, but may then become extrovert, such as verbally or physically abusing someone else. At this point, intervention is needed to help the child regain control with little support. Suggested strategies are: Move the child out of the situation in a non-punitive way. Use proximity to the child to show acceptable behavior, e.g., stand next to the child. Use a pre-agreed "signal" to communicate to the child that misery/despair/anxiety is understandable. Offer routine support, e.g., direct the child "just walk and do not talk". Take a quiet stroll with the child. Redirect, e.g., help the child to concentrate on something is not upsetting. Acknowledge the student's difficulties, e.g., say "I understand that this is difficult". While it is important to understand interventions that can calm a crisis, adults also need to know what behaviors are likely to escalate into a crisis for children with ASD.

Behaviors that can cause anger and escalate into a crisis include: raising the voice, drawing of unwarranted conclusions, top-down management, holding the student in a corner, causing anger, over-generalizing the student's behavior, preaching, unsubstantiated accusations, sarcasm, "parroting" the child, bearing grudges, making comparisons with others, using unnecessary force, not listening, making insulting remarks.

The stage of rage: This follows the first stage, and the behavior shown here (often beyond the conscious control of the child) may be externalized (e.g., screaming, biting, kicking, etc.) or internalized (withdrawal). The most effective way to help with this behavior is to bring the student into a situation where he/she can regain control. The teacher needs to have a plan of support from other staff, to move other students from the area. When choosing an intervention at this stage, it is important to understand the function of the targeted behaviour, in order to prevent the anger circle from escalating. A functional evaluation helps identify a given behavior and is the first step in developing effective interventions. Understanding the reason behind a behavior improves the effectiveness of the intervention.

The recovery stage: Following an episode, some children with ASD may become remorseless, rude and distraught, or deny what they did as they cannot fully remember it. In some cases, they are exhausted from their physical stress and need to sleep. Intervention must take place when the student can understand and accept, otherwise the intervention itself may trigger the cycle in a more intensive form, leading faster to anger. During the recovery process, the adults must work with the students to help them get back into their routine. This can be accomplished by directing them towards actions that can be accomplished easily, motivated by special interests.

The best intervention is prevention, which is best achieved by a multi-faceted approach, consisting of directives on strategies that increase social understanding and problem solving, techniques to facilitate self-understanding, self-relaxing methods and avoidance of anxiety and anger triggers

Enrichment of the school curriculum with sessions for the development of comprehension on anxiety causes and triggers is suggested, for the everyday training of pupils (Nauta et al., 2004). Training of children, with clarification of meanings and demystification of sources of anxiety is proposed as a natural from of management. Teachers in cooperation with parents recognize the manifestations of anxiety and try to remove anxiety triggers and sensory stimuli, and to adapt and control the school environment and conditions. They implement programs 
before the appearance of manifested behavior. Cooperation between parents and teachers, with the use of videos, to discuss and comment on the child's behavior can provide a better picture of the children's reactions.

These are all strategies that are used in schools where children with ASD are enrolled, and by parents in the home environment. Their degree of success is largely undocumented, as there have been no "before" and "after" studies, with measurement of anxiety by recognized instruments. Evidence-based programs have been scarce

\subsection{Specific Intervention Programs for Management of Anxiety in School-Age Children With ASD}

Three programs were reviewed here of structured intervention for the management of anxiety in children and young people with ASD, with a view to enhancing their inclusion in the school environment and in the wider social setting. The success of such programs is measured by reduction in the anxiety levels of the participants and improvement in their social skills. The ultimate success of intervention will be judged by the retention and maintenance of the skills in the longer term.

The three programs are the PRECISE framework (Kim et al, 2000; Chalfant et al., 2007), the program conducted in the Sutherland House School (Oono, Honey, McConachie, 2013), and the UCLA PEERS program (Laugeson et al., 2014). They provide working examples of the conviction of their designers that to provide the maximum benefit, intervention programs for this population should be conducted within a structured framework, with sessions at regular intervals over a specified period of time, and should be enjoyable. The programs should allow for flexibility and should involve the participants themselves actively and their parents/guardians, in cooperation with those responsible for their medical and mental health care, who will have made the diagnosis of anxiety and who will coordinate any other treatment, in particular possible medication for anxiety. The efficacy of the PEERS program has been documented (White et al., 2007; Reichow \& Volkmar, 2010; Laugeson et al., 2014).

The review revealed that although many interventions for the identification and management of anxiety in children with ASD appear to be being applied in the school setting, reports of structured intervention programs are few. Specific constraints to the design, application and evaluation of such programs include the difficulty of diagnosis of anxiety in this population, and the lack of appropriate means of its measurement, as most of the instruments have been designed for and tested with children and young people of TD.

\section{Conclusion}

Management of anxiety in children and young people with ASD in the school environment is not a simple task. Recognition of their anxiety symptoms may not be easy as they overlap with the characteristics of ASD, and instruments for measurement of anxiety level were designed for children of TD and may not be appropriate. Their anxiety contributes to the difficulties they experience in social inclusion both in the school environment and in the wider social setting. In the treatment of anxiety in this population, in addition to medication, various behavioural and cognitive approaches are employed, and in particular CBT. In an effort to address the anxiety of students with ASD, schools are increasingly incorporating modifications in the environment and curriculum. There is evidence that a structured program in the school with regular sessions and specific techniques, and with parental involvement, can produce successful alleviation of anxiety symptoms and enhanced social inclusion. There is a need for more such programs, with planned evaluation of their efficacy and of the persistence of their effect.

\section{References}

Alfano, C. A., Beidel, D. C., \& Turner, S. M. (2006). Cognitive correlates of social phobia among children and adolescents. Journal of Abnormal Child Psychology, 34, 189-201. https://doi.org/10.1007/s10802-005-9012-9

American Psychiatric Association. (2013). Diagnostic and statistical manual of mental disorders (5th ed.). Arlington, VA: American Psychiatric Publishing.https://doi.org/10.1176/appi.books.9780890425596

Bellini, S., Peters, J. K., Benner, L., \& Hopf, A. (2007). A meta-analysis of school-based social skills interventions for children with autism spectrum disorders. Remedial and Special Education, 28, 153-162. https://doi.org/10.1177/07419325070280030401

Boardman, A. G., Arguelles, M. E., Vaughn, S., Hughes, M. T., \& Klingner, J. (2005). Special education teachers' views of research-based practices. Journal of Special Education, 39, 168-180. https://doi.org/10.1177/00224669050390030401

Brown, E. J., Turovsky, J., Heimberg, R. G., Juster, H. R., Brown, T. A., \& Barlow, D. H. (1997). Validation of the Social Interaction Anxiety Scale and the Social Phobia Scale across the anxiety disorders. Psychological Assessment, 9(1), 21-27. https://doi.org/10.1037/1040-3590.9.1.21 
Centers for Disease Control and Prevention. (2012). Prevalence of autism spectrum disorders-Autism and developmental disabilities monitoring network, 14 sites, United States. MMW SurveillSumm, 61(3), 1-19.

Chalfant, A. M., Rapee, R., \& Carroll, L. (2007). Treating anxiety disorders in children with high functioning autism spectrum disorders: A controlled trial. Journal of Autism and Developmental Disorders, 37(10), 1842-1857. https://doi.org/10.1007/s10803-006-0318-4

Chan, J. M., Lang, R., Rispoli, M., O'Reilly, M., Sigafoos, J., \& Cole, H. (2009). Use of peer-mediated interventions in the treatment of autism spectrum disorders: A systematic review. Research in Autism Spectrum Disorders, 3, 876-889. https://doi.org/10.1016/j.rasd.2009.04.003

Chang, Y. C., Laugeson, E. A., Gantman, A., Dillon, A. R., Ellingsen, R., \& Frankel, F. (2013).Predicting treatment success in social skills training for adolescents with autism spectrum disorders: The UCLA program for the education and enrichment of relational skills. Autism: The International Journal of Research and Practice. https://doi.org/10.1177/1362361313478995

Dang, K., Bent, S., Lawton, B., Warren, T., Widjaja, F., McDonald, M. G., Breard, M., O'Keefe, W., \& Hendren, R. L. (2017).Integrating Autism Care through a School-Based Intervention Model: A Pilot Study.J Clin Med., 6(10). https://doi.org/10.3390/jcm6100097

Drahota, A., Wood, J. J., Sze, K. M., \& Van Dyke, M. (2011). Effects of cognitive behavioral therapy on daily living skills in children with high-functioning autism and concurrent anxiety disorders. Journal of Autism and Developmental Disorders, 41(3), 257-265. https://doi.org/10.1007/s10803-010-1037-4

Flynn, L., \& Healy, O. (2012). A review of treatments for deficits in social skills and self-help skills is autism spectrum disorder. Research in Autism Spectrum Disorders, 6, 431-441. https://doi.org/10.1016/j.rasd.2011.06.016

Fujii, C., Renno, P., McCleod, B. et al. (2013). Intensive Cognitive Behavioral Therapy for Anxiety Disorders in School-aged Children with autism: A preliminary comparison with treatment-as-usual. School Mental Health, 5(1), 25-37. https://doi.org/10.1007/s12310-012-9090-0

Gadow, K. D., Devincent, C. J., Pomeroy, J., \& Azizian, A. (2005). Comparison of DSM-IV symptoms in elementary school-age children with PDD versus clinic and community samples. Autism, 9(4), 392-415. https://doi.org/10.1177/1362361305056079

Ghahari, S., Hassani, H., \& Purmofrad, M. (2017). Pragmatic Competency and Obsessive-Compulsive Disorder: A Comparative Assessment with Normal Controls. $J$ Psycholinguist Res., 46(4), 863-875.https://doi.org/10.1007/s10936-016-9467-6

Gresham, F. M.., Watson, T. S., \& Skinner, C. H. (2001). Functional Behavioral Assessment: Principles, Procedures, and Future Directions. School Psychology Review Spring 2001, 30(2), 156-172.

Harper, C. B., Symon, J. B., \& Frea, W. D. (2008). Recess is time-in: Using peers to improve social skills of children with autism. Journal of Autism and Developmental Disorders, 38(5), 815-826. https://doi.org/10.1007/s10803-007-0449-2

Hart, J. E., \& Whalon, K. J. (2011). Creating social opportunities for students with autism spectrum disorder in inclusive settings. Intervention in School and Clinic, 46, 273-279. https://doi.org/10.1177/1053451210395382

Hess, K. L., Morrier, M. J., Heflin, L. J., \& Ivey, M. L. (2008). Autism treatment survey: Services received by children with autism spectrum disorders in public school classrooms. Journal of Autism and Developmental Disorders, 38(5), 961-971. https://doi.org/10.1007/s10803-007-0470-5

January, A. M., Casey, R. J., \& Paulson, D. (2011). A meta-analysis of classroom-wide interventions to build social skills: Do they work?. School Psychology Review, 40, 242-256.

Joseph, R., \& Flusberg, H. T. (2004).The relationship of theory of mind and executive functions to symptom type and severity in children with Autism. Development and Psychopathology, 16(1), 137-55. https://doi.org/10.1017/S095457940404444X

Kamps, D. M., Leonard, B. R., Vernon, S., Dugan, E. P., Delquadri, J. C., Gershon, B., et al. (1992). Teaching social skills to students with autism to increase peer interactions in an integrated first-grade classroom. Journal of Applied Behavior Analysis, 25(2), 281-288. https://doi.org/10.1901/jaba.1992.25-281

Kasari, C., Rotheram-Fuller, E., Locke, J., \& Gulsrud, A. (2012). Making the connection: Randomized controlled 
trial of social skills at school for children with autism spectrum disorders. Journal of Child Psychology and Psychiatry, 53, 431-439. https://doi.org/10.1111/j.1469-7610.2011.02493.x

Kim, J. A., Szatmari, P., Bryson, S. E., Streiner, D. L., \& Wilson, F. J. (2000). The prevalence of anxiety and mood problems among children with autism and Asperger syndrome. Autism, 4(2), 117-132. https://doi.org/10.1177/1362361300004002002

Lang, R., Regester, A., Lauderdale, S., Ashbaugh, K., \& Haring, A. (2010). Treatment of anxiety in autism spectrum disorders using cognitive behaviour therapy: A systematic review. Developmental Neurorehabilitation, 13(1), 53-63. https://doi.org/10.3109/17518420903236288

Lang, R., \& Page, S. (2011). Benefits of teacher collaboration across varying stages of the research process. Intervention in School and Clinic, 46, 230-234.https://doi.org/10.1177/1053451210389031

Laugeson, E.A., Ellingsen, R., Sanderson, J., Tucci, L, \& Bates, S. (2014). The ABC's of teaching social skills to adolescents with autism spectrum disorder in the classroom: the UCLA PEERS (®) Program. $J$ Autism DevDisord. 44(9), 2244-56. https://doi.org/10.1007/s10803-014-2108-8

Lecavalier, L., Wood, J. J., Halladay, A. K., Jones, N. E., Aman, M. G., Cook, E. H., ... Scahill, L. (2014). Measuring anxiety as a treatment endpoint in youth with autism spectrum disorder. $J$ Autism Dev Disord., 44(5), 1128-43. https://doi.org/10.1007/s10803-013-1974-9

Leyfer, O. T., Folstein, S. E., Bacalman, S., Davis, N. O., Dinh, E., Morgan, J., ... Lainhart, J. E. (2006). Comorbid psychiatric disorders in children with autism: interview development and rates of disorders. $J$ Autism Dev Disord, 36(7),849-61. https://doi.org/10.1007/s10803-006-0123-0

Licciardello, C. C., Harchik, A. E., \& Luiselli, J. K. (2008). Social skills intervention for children with autism during interactive play at a public elementary school. Education and Treatment of Children, 31(1), 27-37. https://doi.org/10.1353/etc. 0.0010

Lord, C., Rutter, M., DiLavore, P. C., \& Risi, S. (2002). Autism diagnostic observation schedule. Los Angeles: Western Psychological Services.

MacNeil, B. M., Lopes, V. A., \& Minnes, P. M. (2009). Anxiety in children and adolescents with autism spectrum disorders.Research in Autism Spectrum Disorders, 3(1), 1-21. https://doi.org/10.1016/j.rasd.2008.06.001

Matson, J. L., Matson, M. L., \& Rivet, T. T. (2007). Social-skills treatments for children with autism spectrum disorders. Behavior Modification, 31, 682-707. https://doi.org/10.1177/0145445507301650

Moree, B. N., \& Davis III, T. E. (2010). Cognitive-behavioral therapy for anxiety in children diagnosed with autism spectrum disorders: Modification trends. Research in Autism Spectrum Disorders, 4, 346-354. https://doi.org/10.1016/j.rasd.2009.10.015

Morrison, L., Kamps, D., Garcia, J., \& Parker, D. (2001). Peer mediation and monitoring strategies to improve initiations and social skills for students with autism. Journal of Positive Behavior Interventions, 3(4), 237-250. https://doi.org/10.1177/109830070100300405

Moote, G. T., Smyth, N. J., \& Wodarski, J. S. (1999). Social skills training with youth in school settings: A review. Research on Social Work Practice, 9, 427-465.https://doi.org/10.1177/104973159900900403

Myles, B. (2003). Behavioral forms of stress management for individuals with Asperger syndrome. Child and

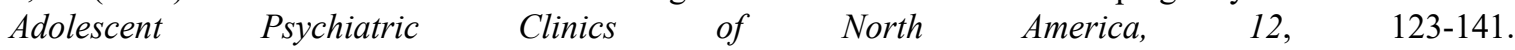
https://doi.org/10.1016/S1056-4993(02)00048-2

Nadeau, J., Sulkowski, M. L., Ung, D., Wood, J. J., Lewin, A. B., Murphy, T. K., et al. (2011). Treatment of comorbid anxiety and autism spectrum disorders. Neuropsychiatry, 1(6), 567-578. https://doi.org/10.2217/npy.11.62

Nauta, M. H., Scholing, A., Rapee, R. M., Abbott, M., Spence, S. H., \& Waters, A. (2004). A parent-report measure of children's anxiety: Psychometric properties and comparison with child report in a clinic and normal sample. Behaviour Research and Therapy, 42(7), 813-839. https://doi.org/10.1016/S0005-7967(03)00200-6

O'Nions, E., Happé, F., Evers, K., Boonen, H., \& Noens, I. (2017). How do Parents Manage Irritability, Challenging Behaviour, Non-Compliance and Anxiety in Children with Autism Spectrum Disorders? A Meta-Synthesis. J Autism DevDisord. https://doi.org/10.1007/s10803-017-3361-4

Oono, I. P., Honey, E. J., \& McConachie, H. (2013). Parent-mediated early intervention for young children with 
autism spectrum disorders (ASD). Cochrane Database Syst Rev, 30(4), CD009774. https://doi.org/10.1002/14651858.CD009774.pub2

Piers, E. V., Harris, D. B., \& Herzberg, D. S. (2002). Piers-Harris Children's Self-Concept Scale, Manual (2nd ed.). Los Angeles, CA: Western Psychological Services.

Pierce, K., \& Schreibman, L. (1997). Multiple peer use of pivotal response training to increase social behaviors of classmates with autism: Results from trained and untrained peers. Journal of Applied Behavior Analysis, 30(1), 157-160. https://doi.org/10.1901/jaba.1997.30-157

Pine, D. S., Cohen, P., Gurley, D., Brook, J., \& Ma, Y. (1998).The risk for early-adulthood anxiety and depressive disorders in adolescents with anxiety and depressive disorders. Archives of General Psychiatry, 55(1), 56. https://doi.org/10.1001/archpsyc.55.1.56

Powers, M., Gordon.Asmundson, J. G., \& Smits, J. (2016). Exercise for mood and anxiety disorders: The state-of-the science. Cogn Behav Ther., 44(4), 237-239. https://doi.org/10.1080/16506073.2015.1047286

Rao, P. A., Beidel, D. C., \& Murray, M. J. (2008). Social skills interventions for children with Asperger's syndrome or high-functioning autism: A review and recommendations. Journal of Autism and Developmental Disorders, 38, 353-361. https://doi.org/10.1007/s10803-007-0402-4

Reaven, J. A. (2009). Children with high-functioning autism spectrum disorders and co-occurring anxiety symptoms: implications for assessment and treatment. J Spec Pediatr Nurs., 14(3), 192-9. https://doi.org/10.1111/j.1744-6155.2009.00197.x

Reaven, J., Blakely-Smith, A., Culhane-Shelburne, K., \& Hepburn, S. (2012). Group cognitive behavior therapy for children with high-functioning autism spectrum disorders and anxiety: A randomized trial. $J$ Child Psychology and Psychiatry, 53(4), 410-419. https://doi.org/10.1111/j.1469-7610.2011.02486.x

Reichow, B., \& Volkmar, F. R. (2010). Social skills interventions for individuals with autism: evaluation for evidence-based practices within a best evidence synthesis framework. J Autism Dev Disord., 40(2), 149-66. https://doi.org/10.1007/s10803-009-0842-0

Rudy, B. M., Lewin, A. B., \& Storch, E. A. (2013). Managing anxiety comorbidity in youth with autism spectrum disorders. Neuropsychiatry, 3(4), 411-421. https://doi.org/10.2217/npy.13.53

Sitlington, P. L., Neubert, D. A., Begun, W., Lombard, R., \& Leconte, P. (2007). Assess for success: A practitioner's handbook on transition assessment (2nd ed.). Thousand Oaks, CA: Corwin Press. https://doi.org/10.4135/9781483329611

Sitlington, P. L., \& Clark, G. M. (2007). The Transition Assessment Process and IDEIA 2004 First Published April 1, 2007. Sage Journal, Hammill Institute on Disabilities.https://doi.org/10.1177/15345084070320030201

Simonoff, E., Pickles, A., Charman, T., Chandler, S., Loucas, T., \& Baird, G. (2008). Psychiatric disorders in children with autism spectrum disorders: Prevalence, comorbidity, and associated factors in a population-derived sample. Journal of the American Academy of Child and Adolescent Psychiatry, 47(8), 921. https://doi.org/10.1097/CHI.0b013e318179964f

Sofronoff, K., Atwood, T., \& Hinton, S. (2005).A randomized controlled trial of a CBT intervention for anxiety in children with Asperger syndrome. Journal of Child Psychology and Psychiatry and Allied Disciplines, 46(11), 1152-1160. https://doi.org/10.1111/j.1469-7610.2008.01948.x

Sood, A. (2013). Mayo Clinic Guide to Stress-Free Living. UK. Lifelong Books.

Sukhodolsky, D. G., Bloch, M. H., Panza, K. E., \& Reichow, B. (2013). Cognitive-behavioral therapy for anxiety in children with high-functioning autism: A meta-analysis. Pediatrics, 132(5), e1341-e1350. https://doi.org/10.1542/peds.2013-1193

Syriopoulou Delli, C., Polychronopoulou, S., Kolaitis, G., \& Antoniou, A. S. (2018). Review of interventions for the management of anxiety symptoms in children with ASD. Neuroscience \& Biobehavioral Review. https://doi.org/10.1016/j.neubiorev.2018.10.023

vanSteensel, F. J. A., Bogels, S. M., \& Perrin, S. (2011). Anxiety disorders in children and adolescents with autistic spectrum disorders: A meta-analysis. Clinical Child and Family Psychology Review, 14(3), 302-317. https://doi.org/10.1007/s10567-011-0097-0

Venter, A., Lord, C., \& Schopler, E. (1992). A follow-up study of high-functioning autistic children. Journal of Child Psychology and Psychiatry, 33(3), 489-507. https://doi.org/10.1111/j.1469-7610.1992.tb00887.x 
Vigerland, S., Serlachius, E., Thulin, U., Andersson, G., Larsson, J. O., \& Ljótsson, B. (2017). Long-term outcomes and predictors of internet-delivered cognitive behavioral therapy for childhood anxiety disorders. Behav Res Ther., 90, 67-75. https://doi.org/10.1016/j.brat.2016.12.008

Walkup, J. T., Albano, A. M., Piacentini, J., Birmaher, B., Compton, S. N., Sherrill, J. T., et al. (2008).Cognitive behavioral therapy, sertraline, or a combination in childhood anxiety.New England Journal of Medicine, 359(26), 2753-2766. https://doi.org/10.1056/NEJMoa0804633

Warwick, H., Reardon, T., Cooper, P., Murayama, K., Reynolds, S., Wilson, C., \& Creswell, C. (2017). Complete recovery from anxiety disorders following Cognitive Behavior Therapy in children and adolescents: A meta-analysis. ClinPsychol Rev., 52, 77-91. https://doi.org/10.1016/j.cpr.2016.12.002

White, S. W., Oswald, D., Ollendick, T., \& Scahill, L. (2009).Anxiety in children and adolescents with autism spectrum disorders.Clinical Psychology Review, 29(3), 216-229. https://doi.org/10.1016/j.cpr.2009.01.003

White, S. W., Keonig, K., \& Scahill, L. (2007). Social skills development in children with autism spectrum disorders: A review of the intervention research. Journal of Autism and Developmental Disorders, 37, 1858-1868. https://doi.org/10.1007/s10803-006-0320-x

Wigham, S., \& McConachie, H. (2015). Systematic Review of the Properties of Tools Used to Measure Outcomes in Anxiety Intervention Studies for Children with Autism Spectrum Disorder. PLOS, 21, 201. https://doi.org/10.1371/journal.pone.0085268

Wood, J. J., Drahota, A., Sze, K., Har, K., Chiu, A., \& Langer, D. A. (2009). Cognitive behavioral therapy for anxiety in children with autism spectrum disorders: A randomized, controlled trial. Journal of Child Psychology and Psychiatry, 50(3), 224-234. https://doi.org/10.1111/j.1469-7610.2008.01948.x

\section{Copyrights}

Copyright for this article is retained by the author(s), with first publication rights granted to the journal.

This is an open-access article distributed under the terms and conditions of the Creative Commons Attribution license (http://creativecommons.org/licenses/by/4.0/). 